\title{
Correction to: Improving health promotion through central rating of interventions: the need for Responsive Guidance
}

\author{
Maarten Olivier Kok ${ }^{1,2^{*}}$, Roland Bal ${ }^{1}$, Caspar David Roelofs ${ }^{3}$ and Albertine Jantine Schuit ${ }^{2,4}$
}

\section{Correction}

It has been highlighted that the original manuscript [1] contains a typesetting error in the name of Caspar David Roelofs. This was incorrectly captured as Caspar David Roelefs in the original manuscript which has since been updated.

\section{Affiliations}

1. Department of Gynecology and Obstetrics, GoetheUniversity, Frankfurt, Germany.

2. Division of Preventive Medicine, Institute of Occupational Medicine, Social Medicine and Environmental Medicine, Goethe-University, Frankfurt, Germany.

3. Department of Obstetrics and Gynecology, Keck School of Medicine, University of Southern California, Los Angeles, CA, USA.

4. Department of Preventive Medicine, University of Southern California, Los Angeles, USA.

Received: 1 February 2018 Accepted: 1 February 2018

Published online: 08 March 2018

\section{Reference}

1. Kok MO, Bal R, Roelofs CD, Schuit AJ. Improving health promotion through central rating of interventions: the need for Responsive Guidance. Health Res Policy Syst. 2017;15(1):100.

\footnotetext{
* Correspondence: m.o.kok@vu.nl

${ }^{1}$ Erasmus School for Health Policy and Management, Erasmus University

Rotterdam, Burgemeester Oudlaan 50, 3062 PA Rotterdam, The Netherlands

${ }^{2}$ Amsterdam Public Health Institute, VU University, Amsterdam, The

Netherlands
} 